\title{
Management of Emphysematous Pyelonephritis and Subsequent Renal Functional Outcome
}

\author{
Md. Mohiur Rahman Khan, ${ }^{1}$ Fahmin Rahman, ${ }^{2}$ Shafiqur Rahman, ${ }^{3}$ ATM Mowladad Chowdhury, ${ }^{4}$ Mirza Mahbubul Hasan ${ }^{5}$
}

\begin{abstract}
Background \& objective: Emphysematous pyelonephritis (EPN) is an acute severe necrotizing infection of the renal parenchyma and its surrounding tissues that is caused by the presence of gas in the renal parenchyma, collecting system or perinephric tissue. The present study was intended to assess the functional status of the emphysematous kidney recovered from infection after treatment.
\end{abstract}

Methods: This prospective study was conducted on 50 consecutive cases of emphysematous pyelonephritis, who were admitted in BIRDEM General Hospital from January 2011 to June 2012. Patients with EPN were selected after taking history, clinical examination and radiological image findings. Based on clinical parameter and radiological grading, patients were categorized for medical or surgical intervention. The forms of surgeries were open drainage or nephrectomy. Renal parenchymal destruction more than $50 \%$ on CT required nephrectomy.

Results: The mean age of the patients at diagnosis was $47.5 \pm 11.8$ years (range: $26-70$ years). The patients were predominantly female $(82 \%)$, invariably diabetic and primarily presented with fever $(88 \%)$ and loin pain $(82 \%)$ followed by dysuria $(60 \%)$. Over three-quarters ( $78 \%$ ) of the patients had poor glycemic control (HbA1c $>7 \%)$ and over half (54\%) were classified as having class 1 or 2 disease and the rest had class 3 and 4 diseases. Escherichia coli was the commonest pathogen found in urine cultures (70\%). Over half $(56 \%)$ received medical treatment alone. In the surgical intervention group, patients were mostly toxic with spreading or severe localized infection, fever and were deteriorating or static even after three days of aggressive intravenous antibiotic treatment. Of the 22 patients who underwent surgery, nephrectomy was performed in $8(16 \%)$ and open drainage in $14(28 \%)$ cases. The overall survival rate was $94 \%$. Average serum creatinine level was found to decrease gradually during follow up. The function of the preserved kidney was found to improve in the subsequent follow up.

Conclusion: Emphysematous pyelonephritis predominantly affects diabetic females. Kidney preservation should be the primary target in treating EPN. Adequate resuscitation, diabetic control and parenteral antibiotic are the treatment of choice. Rapid drainage and nephrectomy should be performed in advanced stages. The focus of management of patients with emphysematous pyelonephritis should not only to improve survival but also salvage of the renal unit, for the affected kidney may still function once the infection is eradicated.

Key words: Emphysematous Pyelonephritis, management and Post-treatment renal outcome etc.

\section{Author's information:}

' Dr. Md. Mohiur Rahman Khan, MD, FCPS (Urology), Registrar, Department of Urology, BIRDEM (Bangladesh Institute of Research and Rehabilitation in Diabetes, Endocrine and Metabolic Disorders) General Hospital, 122 Kazi Nazrul Islam Avenue, Dhaka-1000, Bangladesh

${ }^{2}$ Dr. Fahmin Rahman, MBBS, MPH, Department of Public Health, North South University (NSU), Bashundhara, Dhaka-1229, Bangladesh

${ }^{3}$ Dr. Shafiqur Rahman, MBBS, FCPS (Surgery), FCPS (Urology), Associate Professor, Department of Urology, BIRDEM General Hospital \& Ibrahim Medical College, Dhaka.

${ }^{4}$ Prof. ATM Mowladad Chowdhury, FCPS (Surgery), MRCSED, MRCPS, MS (Urology), Department of Urology, BIRDEM General Hospital \& Ibrahim Medical College, Dhaka.

${ }^{5}$ Prof. Mirza Mahbubul Hasan, MBBS, FCPS (Surgery), FRCS(Ed), FICS, FACS, Professor \& Head, Department of Urology, BIRDEM General Hospital \& Ibrahim Medical College, Dhaka.

Correspondence: Dr. Md. Mohiur Rahman Khan, Phone: +880 1727346249 E-mail: babumohiur@yahoo.com 


\section{INTRODUCTION:}

Emphysematous pyelonephritis (EPN) is an acute, severe necrotizing infection of the renal parenchyma and its surrounding tissues that results from the presence of gas in the renal parenchyma, collecting system or perinephric tissue. ${ }^{1,2}$ Emphysematous pyelitis-gas in the collecting system only, has been categorized as a benign condition. ${ }^{3}$ By contrast, EPN requires special attention because of the lifethreatening potential, primarily because of septic complications. It is commonly seen in diabetics and immunocompromised patients. ${ }^{4}$ The clinical features of EPN are indistinguishable from those of severe acute pyelonephritis and the diagnosis can be suspected after a poor response to conventional antibiotic treatment. ${ }^{5}$ Infective insult by gas producing organisms, results in an aggressive necrotizing process that causes severe parenchymal damage and dysfunction of the affected kidney ${ }^{6}$ as evidenced by raised creatinine. The treatment strategies of EPN were to preserve the kidney, but in refractory cases, emergency nephrectomy or open surgical drainage, along with antibiotic therapy are the treatment of choice.

In BIRDEM Hospital a good number of EPN cases are treated by both medical and surgical intervention. Depending on severity of infection, preservation of the kidney is always attempted. Previously the patients were followed up with serum creatinine level as the functional status of the affected kidney. But creatinine becomes affected in case of bilateral infection or toxic influence of severe unilateral infection. Isotope renogram is more suggestive to demonstrate combined and individual renal function. After completion of treatment or clinical recovery from emphysematous kidney, the actual functional outcome of affected kidney can more precisely be evaluated by isotope renogram, imaging and biochemistry. This study was designed to evaluate the subsequent renal functional status of the affected kidney of clinically recovered patients.

\section{METHODS:}

This prospective study was undertaken to assess the functional status of the emphysematous kidney recovered from infection following treatment. The study was conducted over a period of 1 and a $1 / 2$ years from January 2011- June 2012 in the Department of Urology \& the Department of Medicine, BIRDEM General Hospital, Dhaka. The patients having emphysematous pyelonephritis admitted in the Department of Urology or Medicine were the study population. Cases of emphysematous pyelonephritis diagnosed by imaging study (USG or CT scan) were included. However, patients with a recent history of trauma, urinary catheter insertion, and/or drainage and fistula between the urinary tract and bowel were excluded from the study.

After selection of the cases, written consent was taken from them. Based on clinical parameter and radiological grading, patients were categorized for medical or surgical management. The response of treatment was monitored clinically and by abdominal USG. Patients were categorized according to Huang and Tseng CT classification and managed accordingly. Treatment was started by resuscitation of patients in state of shock and blood sugar control, acid base balance correction, appropriate antibiotics. If there was no clinical progress or patients were further deteriorated, open surgical drainage or nephrectomy was preferred. The response to treatment was monitored by USG or Non-contrast computerized tomography (NCCT) After stabilization of the patients' condition, a DTPA (99m Tc-diethylenetriaminepentaacetic acid) renogram scan was done to estimate the differential function of the affected kidney. In the surgical intervention arm, patients were predominantly toxic with spreading or severe localized infection. The temperature was persisting and the conditions of the patients were deteriorating or static even after three days of aggressive intravenous antibiotic treatment. The forms of surgeries were open drainage or nephrectomy. Advanced disease with renal parenchymal destruction more than $50 \%$ on CT warranted nephrectomy. Patients with preserved kidney were followed up at $1^{\text {st }}, 3^{\text {rd }}$ and $6^{\text {th }}$ months interval. Each follow up included clinical examination, laboratory investigations, which among others, included complete blood count, serum creatinine, urine analysis, abdominal USG, radioisotope scan (DTPA renogram at 3 months and 6 months). Data 
were processed and analyzed using computer software SPSS (Statistical Package for Social Sciences), version 16 . The test statistics used to analyze the data were descriptive statistics, Chi-square $\left(\chi^{2}\right)$ Test, Unpaired and Paired t-Test and ANOVA statistics. The level of significance was set at 0.05 and $p<0.05$ was considered significant.

\section{RESULTS:}

Early middle-aged (36-45 years old) and middleaged (46-55 years old) population comprised more than half of the patients (54\%). The mean age of the patients at diagnosis was $47.5 \pm 11.8$ years (range: 26-70 years). The patients were predominantly female (82\%) with male to female ratio roughly being 1:4 (Table-I). The clinical presentation of the patients was variable with fever and loin pain being the most the common complaints ( $88 \%$ and $82 \%$ respectively). Dysuria was the third most common complaint (60\%). Acute renal failure (38\%), thrombocytopenia (22\%), altered sensorium (20\%) and shock (12\%) at admission were warning signs for poor prognosis. Uncontrolled diabetes (glycosylated haemoglobin or HbA1c > 7\%) was found in $78 \%$ of the patients (Table II). Urine cultures were positive in 47 (94\%) patients with Escherichia coli being the predominant organism (70\%) (Table III). Ultrasound diagnosed nearly two-thirds (64\%) of the cases, while abdominal non-contrast CT scan diagnosed EPN in $100 \%$ of cases (Table IV).

TABLE I. Demographic characteristics of the study patients $(n=50)$

$\begin{array}{lccc}\begin{array}{l}\text { Demographic } \\ \text { characteristics }\end{array} & \text { Frequency } & \text { Percentage } & \begin{array}{c}\text { Mean } \pm \text { SD } \\ \text { (range) }\end{array} \\ \text { Age Group (years) } & & & \\ 26-35 & 9 & 18.0 & \\ 36-45 & 14 & 28.0 & \\ 46-55 & 13 & 26.0 & 47.5 \pm 11.8(26-70) \\ 56-65 & 11 & 22.0 & \\ 66-75 & 03 & 06.0 & \\ \text { Sex } & & & \\ \text { Male } & 9 & 18.0 \\ \text { Female } & 41 & 82.0\end{array}$

TABLE II. Demographic characteristics of the study patients $(n=50)$

$\begin{array}{lcc}\text { Clinical presentations } & \text { Frequency } & \text { Percentage } \\ \text { Presentation } & & \\ \quad \text { Fever } & 44 & 88.0 \\ \text { Loin pain } & 41 & 82.0 \\ \text { Dysuria } & 30 & 60.0 \\ \quad \text { Nausea and vomiting } & 11 & 22.0 \\ \text { Warning signs } & & \\ \text { Acute renal failure } & 19 & 38.0 \\ \text { Thrombocytopenia } & 11 & 22.0 \\ \text { Altered sensorium } & 10 & 20.0 \\ \text { Shock } & 6 & 12.0 \\ \text { Glycemic status } & & \\ \text { HbA1c (\%) } & & \\ >7 & 39 & 78.0 \\ <7 & 11 & 22.0\end{array}$

TABLE III. Urine Culture

$\begin{array}{lcc}\text { Organism } & \text { Frequency } & \text { Percentage } \\ \text { Escherichia coli } & 35 & 70.0 \\ \text { Klebsiella } & 7 & 14.0 \\ \text { Pseudomonas } & 2 & 4.0 \\ \text { Proteus } & 3 & 6.0 \\ \text { No growth } & 3 & 6.0 \\ \text { Total } & 50 & 100.0\end{array}$

\begin{tabular}{|lcc|}
\hline TABLE IV. Ultrasonography & & \\
\hline Diagnosis & No of Patents & Percentage \\
\hline EPN & 32 & 64.0 \\
Pyelonephritis & 18 & 36.0 \\
Total & 50 & 100.0
\end{tabular}

According to Huang and Tseng CT classification, CT class II patients formed $38 \%$ followed by class IIIa $30 \%$, class I $16 \%$, class IIIb $14 \%$ cases and class IV $2 \%$ cases. Based on classification of the disease, over half $(56 \%)$ of the patients received medical management, $28 \%$ open drainage and $16 \%$ nephrectomy (Table V). All patients with EPN were initially treated with medical management. Patients who did not improve clinically and by imaging $(n=22)$, needed surgical intervention. Of them organ was preserved in 14 cases and nephrectomy was done in 8 cases. Of the 28 patients who received only medical management $92.8 \%$ survived. Among the patients who received open drainage procedure with kidney preservation, 
majority $(92.8 \%)$ survived. In case of nephrectomized patients survival rate was $100 \%$. The overall survival rate was $94 \%$ (47 out of 50 ). The kidneys were preserved in 39 of 50 patients $(78 \%$ ) (Table VI). Average serum creatinine level was found to decrease gradually in subsequent follow up in comparison to their baseline figure $(p<0.001)$ (Table VII). Patients in whom the kidney was preserved, the difference of creatinine level was found statistically significant $(p<0.024)$ after 6 months (Table VIII). Patients in whom affected kidney was preserved by medical management, the difference in creatinine levels from baseline to endpoint of the study was not found to be statistically significant $(p=0.143)$ (Table IX). Patients in whom the affected kidney was preserved by open drainage, the difference in creatinine levels between baseline and endpoint was also not found to be statistically significant $(p=0.073)$ (Table $X)$. DTPA renogram showed that the mean relative function of the affected kidney was statistically significant $(p<0.001)$ (Table XI). Mean relative function of the affected kidney estimated by DTPA renogram in patients who were treated by medical management significantly improved $(p<0.001)$ (Table XII). Mean relative function of the affected kidney estimated by DTPA renogram in patients treated by open drainage also improved significantly $(p<0.001)$ (Table XIII).

\begin{tabular}{|c|c|c|}
\hline CT Class \& Management & Frequency & Percentage \\
\hline \multicolumn{3}{|l|}{ CT Class } \\
\hline I & 8 & 16.0 \\
\hline ॥ & 19 & 38.0 \\
\hline Illa & 15 & 30.0 \\
\hline IIIb & 7 & 14.0 \\
\hline IV & 1 & 2.0 \\
\hline \multicolumn{3}{|l|}{ Management } \\
\hline Medical management & 28 & 56.0 \\
\hline Open drainage & 14 & 28.0 \\
\hline Nephrectomy & 8 & 16.0 \\
\hline
\end{tabular}

\section{TABLE VI. Management outcome of patients with EPN}

$\begin{array}{lcc}\text { Management } & \text { Survived } & \text { Died } \\ \text { Medical management }(n=28) & 26(92.8) & 2(7.2) \\ \text { Open drainage }(n=14) & 13(92.8) & 1(7.2) \\ \text { Nephrectomy }(n=8) & 8(100.0) & 0(0.0)\end{array}$

Figures in the parentheses denote corresponding percentage

\section{TABLE VII. Change of serum creatinine following treatment}

\begin{tabular}{lcccc}
$\begin{array}{l}\text { Biochemical } \\
\text { value }\end{array}$ & $\begin{array}{c}\text { On admission } \\
(n=50) \\
\text { Mean } \pm S D\end{array}$ & $\begin{array}{c}\text { After } 1 \text { month } \\
(n=47) \\
\text { Mean } \pm S D\end{array}$ & $\begin{array}{c}\text { After } 3 \text { months } \\
(n=47) \\
\text { Mean } \pm S D\end{array}$ & $\begin{array}{c}\text { After } 6 \text { months } \\
(n=47) \\
\text { Mean } \pm S D\end{array}$ \\
\hline S.creatinine & $2.35 \pm 1.43$ & $1.52 \pm 0.52$ & $1.50 \pm 0.49$ & $1.43 \pm 0.43$
\end{tabular}

*Data were analyzed using ANOVA statistics and were presented as mean $\pm S D$; ${ }^{2}$ On admission vs. after 1 month vs. after 3 months vs. after 6 monthsp $<0.001$.

TABLE-VIII. Changes in serum creatinine patients in whom kidney was preserved $(n=39)$

\begin{tabular}{llc}
\hline Follow up & Mean \pm SD & P-value \\
On admission & $1.74 \pm 0.85$ & \\
After 1 months & $1.52 \pm 0.50$ & $0.152^{\text {ns }}$ \\
On admission & $1.74 \pm 0.85$ & \\
After 3 months & $1.49 \pm 0.48$ & $0.09^{\text {ns }}$ \\
On admission & $1.74 \pm 0.85$ & \\
After 6 months & $1.40 \pm 0.43$ & $0.024^{* *}$
\end{tabular}

Data were analyzed by Paired t-test $*$ Significant $n s=$ Not significant

TABLE-IX. Changes in serum creatinine patients in whom kidney was preserved by medical management $(n=26)$

$\begin{array}{llc}\text { Follow up } & \text { Mean } \pm \text { SD } & \text { P-value } \\ \text { On admission } & 1.72 \pm 0.86 & 0.471^{\text {ns }} \\ \text { After } 1 \text { months } & 1.58 \pm 0.55 & \\ \text { On admission } & 1.72 \pm 0.86 & 0.314^{\text {ns }} \\ \text { After } 3 \text { months } & 1.53 \pm 0.53 & \\ \text { On admission } & 1.72 \pm 0.86 & 0.143^{\text {ns }} \\ \text { After } 6 \text { months } & 1.44 \pm 0.46 & \end{array}$

Data were analyzed by Wilcoxon Signed Rank Test ** Significant $\mathrm{ns}=$ Not significant

TABLE-X. Changes in serum creatinine in patients whom Wilcoxon Signed Ranktest kidney was preserved by open drainage $(n=13)$

$\begin{array}{lrc}\text { Follow up } & \text { Mean } \pm \text { SD } & \text { P-value } \\ \text { On admission } & 1.78 \pm 0.85 & \\ \text { After } 1 \text { months } & 1.39 \pm 0.35 & 0.152^{\text {ns }} \\ \text { On admission } & 1.78 \pm 0.85 & \\ \text { After } 3 \text { months } & 1.40 \pm 0.37 & 0.168^{\text {ns }} \\ \text { On admission } & 1.78 \pm 0.85 & \\ \text { After } 6 \text { months } & 1.32 \pm 0.36 & 0.073^{\text {ns }}\end{array}$

Data were analyzed by Wilcoxon Signed Rank Test ** Significant ns $=$ Not significant

TABLE-XI. Mean relative function of the affected kidney ( $n=39$ ) estimated by DTPA renogram

$\begin{array}{lll}\text { Follow up } & \text { Mean } \pm \text { SD } & \text { P-value } \\ \text { On admission } & 19.24 \pm 2.49 & \\ \text { After } 3 \text { months } & 27.79 \pm 5.48 & <0.001^{* *} \\ \text { On admission } & 19.24 \pm 2.49 & \\ \text { After } 6 \text { months } & 27.93 \pm 5.30 & <0.001^{* *}\end{array}$

Data were analyzed by Wilcoxon Signed Rank Test ** Significant $\mathrm{ns}=$ Not significant 
Table-XII. Mean relative function of the affected kidney estimated by DTPA renogram in patients who were treated by medical management $(n=26)$

$\begin{array}{lll}\text { Follow up } & \text { Mean } \pm \text { SD } & \text { P-value } \\ \text { On admission } & 20.15 \pm 2.39 & <0.001^{* *} \\ \text { After } 3 \text { months } & 30.32 \pm 4.47 & \\ \text { On admission } & 20.15 \pm 2.39 & <0.001^{* *} \\ \text { After } 6 \text { months } & 29.88 \pm 5.12 & \end{array}$

Data were analyzed by Wilcoxon Signed Rank Test ** Significant ns $=$ Not significant

\begin{tabular}{|c|c|c|}
\hline Follow up & Mean $\pm S D$ & P-value \\
\hline On admission & $17.42 \pm 1.50$ & \multirow{2}{*}{$<0.001^{* *}$} \\
\hline After 3 months & $22.73 \pm 3.43$ & \\
\hline On admission & $17.42 \pm 1.50$ & \multirow{2}{*}{$<0.001^{* *}$} \\
\hline After 6 months & $24.03 \pm 3.07$ & \\
\hline
\end{tabular}

Data were analyzed by Wilcoxon Signed Ranktest ** Significant $\mathrm{ns}=$ Not significant

\section{DISCUSSION:}

Emphysematous pyelonephritis (EPN) is a lifethreatening infection characterized by the presence of gas in the renal parenchyma $\&$ the surrounding tissues. Diabetes mellitus is the most frequently reported predisposing factor for developing EPN, as it comprises $80-100 \%$ of patients. ${ }^{7,8}$ In our study $100 \%$ patients were diabetic. Our study showed that the disease had a female predominance $(82 \%)$. Increased susceptibility to urinary tract infection seems to be the reason for the higher incidence in females. Most of the studies have reported the disease to occur predominantly in females. ${ }^{8,9}$ The clinical presentation of EPN in the present study is similar to those reported previously with loin pain and fever being the predominant symptom. ${ }^{9}$ Huang et al ${ }^{10}$ showed fever $(79 \%)$ and flank pain $(71 \%)$ as the most common symptoms. The same was observed by Tang et al in their study. ${ }^{11}$ Dysuria (60\%) was next to fever and loin pain. However, Khaira et al ${ }^{12}$ in their study showed that dysuria was the most common complaint (84.2\%) followed by fever $(79 \%)$, and pain in the loin $(68.4 \%)$. In our study urine culture was positive in $94 \%$ of cases \& Escherichia coli was the predominant organism
(70\%). Consistent with this finding, Somani et al. ${ }^{13}$ showed that Escherichia coli was the most common organism $(65.6 \%)$ in urine cultures, followed by Klebsiella (19.5\%) \& mixed organisms (10\%). Huang and Tseng ${ }^{10}$ reported $98 \%$ cases of urine culture to be positive.

It is said that high glucose level in tissue (as is found in patients of uncontrolled diabetes) provides a substrate for bacteria to produce carbon dioxide and hydrogen by the fermentation of sugar. We found evidence of uncontrolled diabetes ( $\mathrm{HbA} 1 \mathrm{C}>7 \%$ ) in $78 \%$ of our cases. Park et al. $^{8}$ also reported poorly controlled sugars in $76 \%$ of their cases. Huang et $\mathrm{al}^{10}$ also observed that $72 \%$ of their cases with poor control of sugars $(\mathrm{HbA} 1 \mathrm{C}>8 \%)$.

Radiological detection of gas in and around the kidney is diagnostic for EPN. USG is a good screening method but non-contrast CT scan was reported to have the highest diagnostic accuracy $(100 \%)$ for EPN. ${ }^{13}$ In the present study, USG helped to diagnose definite EPN in $64 \%$ of cases, whereas NCCT confirmed EPN in $100 \%$ cases. Therefore, non-contrast CT is the investigation of choice not only for diagnosis of EPN but also for classifying patients into different categories. ${ }^{10,13}$

The accepted treatment of EPN until the late 1980 s has been emergency nephrectomy and or surgical drainage together with antibiotic therapy, resulting in a reported mortality rate of $40-50 \% .{ }^{1}$ During the last decade there has been a gradual shift toward a nephron-sparing management. The reasons for this change were the high mortality rate of emergency nephrectomy $(17.6-40 \%)^{6,12}$ and advances in image-guided procedures for drainage of the gas and infected fluid, using percutaneous tube drain. ${ }^{13,14}$ Somani and colleagues. ${ }^{13}$ recommended that the treatment strategies of EPN should be medical management alone, percutaneous drainage with medical management, medical management with emergency nephrectomy \& percutaneous drainage plus medical management plus emergency nephrectomy. In a study conducted by Koh et al. ${ }^{15}$ recommended that drainage without nephrectomy should be the initial approach unless the affected kidney is 
extensively destroyed. Nephrectomy as an emergency procedure in the presence of gross sepsis is different and carries increased risks. Rapid open drainage is, therefore, preferable when conditions allow. It is successful in controlling the infection and if no recovery occurs in renal function, nephrectomy could be undertaken electively. They also reported that they had not found percutaneous drainage useful because the pus was too viscous to drain via the percutaneous catheter and the multiloculeted nature of these infections usually makes complete drainage difficult.

In the present study the treatment strategies of EPN was to preserve the kidney. Based on clinical parameter and radiological grading patients were categorized for medical or surgical intervention. The patients in the surgical intervention arm were mostly toxic with spreading or severe localized infection, have had high temperature, deteriorating or static even after three days of aggressive intravenous antibiotic treatment. The surgeries done were either open drainage or nephrectomy. In this study 22 cases underwent surgery. Nephrectomy was performed in 8 patients and 14 underwent open drainage. In a study, Aswathaman et $\mathrm{al}^{14}$ reported that medical management alone was successful in $40 \%$ of cases, while in another study Shoker et al.? showed success rate after medical management alone to be $66 \%$. Like Aswathaman et al. ${ }^{14}$ we also observed that patients who had no warning signs such as thrombocytopenia, shock, altered sensorium, acute renal failure and patients with localized disease (class 1 and 2 according to the Huang classification) are the good candidates for medical management. Chen and associates ${ }^{9}$ suggested that percutaneous drainage is safe and effective for EPN and can result in cure. In a study Khaira et $\mathrm{al}^{12}$ suggested that even for patients with extensive EPN cases (class $3 \& 4$ ) with no other warning signs, percutaneous drainage combined with antibiotic treatment may be attempted, because of high success rate which allows preserving the kidney. In a meta-analysis conducted by Somani et al. ${ }^{16}$ the success rate after percutaneous drainage with medical management was $90-100 \%$. However, we could not perform percutaneous drainage due to lack of logistic support.

In our study the management strategy for the patients with EPN was medical management. Those who did not improve clinically and by imaging needed surgical drainage. Previously EPN was considered as a surgical emergency because of the high mortality rate. Falagas et al. ${ }^{4}$ conducted a meta-analysis and found an overall mortality rate of $25 \%$. Kapoor and associates ${ }^{16}$ reported a mortality rate of $13 \%$ in 39 patients with EPN. They concluded that altered mental status, thrombocytopenia, renal failure \& severe hyponatreamia at presentation were significantly associated with death. In our study the morality rate was significantly lower $(6 \%)$. The lower mortality rate in the present study and that of Aswathaman et al. ${ }^{14}$ could be the result of efficient resuscitation followed by early drainage. In the present study the average serum creatinine level was found to decline gradually in subsequent follow up in comparison to the baseline figure. In the study by Khaira et al. ${ }^{12}$ the serum creatinine level came down to normal level $(1.86 \pm 0.45 \mathrm{mg} / \mathrm{dl})$ by 6 months in all cases which compares well with the findings of the present study. In the management of patients with emphysematous pyelonephritis the focus should not only be to improve survival but also to salvage of the renal unit. The remaining nephrons in the affected kidney might still function once the infection is eradicated. In our study the mean relative function of the affected preserved kidney was found to increase in subsequent follow ups in comparison with the baseline functional status. Aswathaman et al. ${ }^{14}$ also reported that those who were not nephrectomized, the mean relative function of the affected kidney was $42 \%$. In another study El-Nahas et al. ${ }^{17}$ recommended that kidney preservation should be the primary goal in the treatment of EPN when the differential renal clearance is $>10 \%$. Therefore, the best treatment strategy should be the one that improve the patient's survival and at the same time maximizes renal salvage. 


\section{CONCLUSION:}

Emphysematous pyelonephritis predominantly affects diabetic females. Diabetes \& urinary tract infection are the predisposing factors for the disease. Escherichia coli is the commonest organism causing the disease. Kidney preservation should be the primary target in treating EPN. Adequate resuscitation, diabetic control and parenteral antibiotic is the treatment of choice for limited form of the disease (CT class I \& II). Rapid drainage and nephrectomy should be performed in advanced stages. Early recognition of the disease and appropriate management is of utmost importance, for favorable functional outcome of the preserved kidneys.

\section{REFERENCES:}

1. Michaeli J, Mogles P, Perlberg S, Heiman S, Caine M. Emphysematous Pyelonephritis. J Urol 1984;131: 203-7.

2. Pontin AR, Barnes RD, Joffe J, Kahn D. Emphysemotous Pyelonephritis in diabetic patients. $\mathrm{Br} \mathrm{J} \mathrm{Urol}$ $1995 ; 75: 71-4$.

3. Roy C, Pfleger, DD, Lang H, Saussire CC, Jacqmin D. Emphysematous pyelitis: findings in five patients. Radiology 2001;218:647-50.

4. Falagas ME, Alexiou VG, Gianno-Poulou KP, Siempos II. Risk factors for mortality in patients with emphysematous pyelonephritis: a meta- analysis. J Urol 2007; 178:880-5.

5. Dutta P, Bhansali A, Singh SK. Presentation \& outcome of emphysematous renal tract disease in patients with diabetes mellitus. Urol Int 2007;78:13-22.

6. Ahlering TE, Boyd SD, Hamilton CL. Emphysematous pyelonephritis: a 5-year experience with 13 patients. J Urol 1985;134:1086-8.

7. Shokeir AA, El-Azab M, Mohsen T, Diosly T. Emphysematous pyelonephritis. A 15 year experience with 20 cases. urology 1997;49:343-6.

8. Park BS, Lee S, Wha Kim Y, Sik Huh J, Kim J, Chang SG. Outcome of nephrectomy and kidney-preserving procedures for the treatment of emphysematous pyelonephritis. Scand J Urol Nephrol 2006;40(4):332-8.

9. Chen MT, Huang $\mathrm{CN}$, Chou $\mathrm{YH}$, Huang $\mathrm{CH}$, Chiang $\mathrm{CP}$, Liu GC. Percutaneous drainage in the treatment of emphysematous pyelonephritis: 10 years experience. J urol 1997;157:1569-73.
10. Huang JJ, Tseng CC. Emphysematous pyelorephritis:clinicoradilogical classification, management, prognosis and pathogenesis. Arch Intern Med 2000;60: 797-805.

11. Tang HJ, Li CM, Yen MY, Chen YS, Wann SR, Lin HH, Lee SS, Liu YC. Clinical characteristics of emphysematous pyelorephritis. J Microbiol Immunol Infect 2001;34: 125-30.

12. Khaira A, Gupta A, Rana DS, Gupta A, Bhalla A, Khullar $D$. Retrospective analysis of clinical profile: prognostic factors and outcome of 19 patients of emphysematous pyelonephritis. Int Urol Nephrol 2009;41:956-66.

13. Somani BK, Nabi G, Thorpe P. Is percutaneous drainage the new gold standard in the management of emphysematous pyelonephritis? Evidence from a systemic review. J urol 2008;179:1844-9.

14. Aswathman K, Gopalakrishnan G, Gananaraj L, Chacko NK, Kekre NS, Devasia A. Emphysematous pyelonephritis outcome with conservative management. Urology 2008;71:1007-9.

15. Koh $\mathrm{KBH}$, Lee $\mathrm{SH}$. Emphysematous pyelonephritis: drainage or nephrectomy? Br J urol 1993;71:609-11.

16. Kapoor R, Mureganandham K, Gulics AK, Singla M, Agrawal S, Mandhani A. Predictive factors for mortality and need for nephrectomy in patients with emphysemaotus pyelorephritis. BJU Int 2010;105:986-9.

17. El-Nahas AR, Shokeir AA, Eziyi AK, Barakat TS, Tijani $\mathrm{KH}$, El-Diasty T, Eneina H. Kidney preservation protocol for management of emphysematous pyelonephritis: Treatment modalities and follow-up. Arab Journal of Urology $2011 ; 9(3): 185-9$. 